carry out appraisals and guide the career development and training programme of research staff.

Conclusion The Global Health Network has created a flexible method and set of tools (PDS) to support researchers and teams to document their professional career and core competencies. It enables individuals and groups to easily identify and track capacity development; an essential requirement for conducting effective health research.

\section{PO 8392 SPUTUM MYCOBACTERIUM LOAD AND CYTOKINES BIOMARKER OF STIMULATED WHOLE BLOOD CELLS IN SPUTUM SMEAR-NEGATIVE PULMONARY TUBERCULOSIS SUDANESE PATIENTS}

Mona Omer. Institute of Endemic Diseases, University of Khartoum, Sudan

\subsection{6/bmjgh-2019-EDC.82}

Background Improvement of the diagnosis of smear-negative pulmonary tuberculosis (PTB) patients and identification of possible immune factors associated with the negative result of sputum will enable early and accurate diagnosis of smear-negative PTB. This study aimed to measure the Mycobacterium load in sputum samples of smear-negative patients and identify cytokines markers associated with smear-negative active pulmonary tuberculosis.

Methods Sputum and heparinised blood samples were collected from 40 smear-negative, 40 smear-positive PTB patients and 21 healthy controls. All sputum samples were analysed by direct $\mathrm{ZN}$ stain and conventional PCR to confirm the infection and characterise the bacteria. The load of bacteria in sputum samples was measured using real-time PCR. Blood samples were stimulated with sonicated MTB H37Rv. TH1 (TNF- $\alpha$, IFN- $\gamma$, IL- 1 $\beta$ ) and TH2 (IL-10) cytokines were measured using ELISA technique.

Results Eight patients were grade $3+, 23$ were grade $2+, 9$ were grade $1+$ and 40 were negative on smear. $87.5 \%$ of smear-negative patients were positive by PCR. Smear-negative PTB patients produced high concentration of IFN- $\gamma$ compared with smear-positive. IL-10 and TNF- $\alpha$ concentration were significantly lower in smear-negative compared with smear-positive. IL-1 $\beta$ was not significantly different between smearnegatives and smear-positives. Both smear-negative and smearpositive samples produced significantly high IL-10 and TNF- $\alpha$ cytokine compared with the healthy controls, while IFN- $\gamma$ production was significantly lower in MTB patients. A highly significant correlation between MTB load and cytokines was detected. The mean concentration of IFN- $\gamma$ was higher in stimulated blood samples of patients with lower bacterial load. In contrast, IL-10 and TNF- $\alpha$ concentration were higher in patients with high bacterial load. The TNF- $\alpha$ and IL-1 $\beta$ were good biomarkers for diagnosis of smear-negatives.

Conclusion Smear-negative PTB produced high TH1 cytokine and low regulatory cytokine compared to smear-positive.

\section{PO 8394 SOUTH-SOUTH AND NORTH-SOUTH CAPACITY STRENGTHENING WITHIN THE SCREENTB CONSORTIUM: WHAT HAVE WE LEARNT?}

${ }^{1}$ Hazel Dockrell ${ }^{*},{ }^{2}$ Claudia Schacht, ${ }^{3}$ Gerhard Walzl. 'London School of Hygiene and Tropical Medicine, UK; ${ }^{2}$ LINQ management GmbH, Berlin, Germany; ${ }^{3}$ Stellenbosch University, South Africa

10.1136/bmjgh-2019-EDC.83
Background Most research consortia and multicentre trials include capacity strengthening as one of their objectives. Activities are included in annual reports but the overall success or otherwise of these is hard to evaluate.

Methods The training and capacity building work package in the EDCTP2-funded ScreenTB Consortium includes support for the individual career development of young researchers. We have made mentoring the central activity, building on what we had learnt in the previous AE-TBC Consortium. We carried out formal training sessions and provided dedicated time-slots for meetings of mentee and mentor during annual meetings. We also introduced the concept of personal development plans through presentations and small group work.

Results Formal timetabled presentations and mentoring sessions have helped make capacity strengthening work. Challenges and solutions have been identified in group sessions and will be presented. This has enabled us to evaluate what works well and what is more challenging, when including capacity strengthening activities within a consortium with 5 African and 3 European partners.

Conclusion Dedicated time and commitment are required to make capacity strengthening work, but when it does, mentoring and personal development planning can provide both African and European researchers with an impartial opportunity to find solutions to their current challenges and to discuss their longer-term goals.

\section{PO 8397 VIRAL SUPPRESSION AMONG CAMEROONIAN ADULTS, ADOLESCENTS AND CHILDREN RECEIVING ANTIRETROVIRAL THERAPY IN THE 'TEST \& TREAT' ERA}

${ }^{1}$ Joseph Fokam*, ${ }^{1}$ Samuel M Sosso, ${ }^{2}$ Rina E Djubgang Mbadie, ${ }^{1}$ Yagai Bouba,

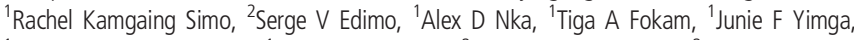
${ }^{1}$ Désiré A Takou Komego, ${ }^{1}$ Sylvie Moudourou, ${ }^{2}$ Marinette Ngo Nemb, ${ }^{2}$ Serge C Billong, ${ }^{2}$ Jean-Bosco Nfetam Elat, ${ }^{3}$ Vittorio Colizzi, ${ }^{1}$ Alexis Ndjolo. ${ }^{1}$ CIRCB: Chantal BIYA International Reference Centre for research on HIVIAIDS prevention and management, Yaounde, Cameroon; ${ }^{2}$ Central Technical Group, National AIDS Control Committee, Yaounde, Cameroon; ${ }^{3}$ UNESCO BOARD of Biotechnology, University of Rome Tor Vergata, Rome, Italy

\subsection{6/bmjgh-2019-EDC.84}

Background Global efforts in meeting the 90-90-90 targets reveal that $70 \%$ of infected people know their HIV status, $77 \%$ of these are receiving antiretroviral therapy (ART) and $82 \%$ of treated patients have viral suppression. Since launching the 'test and treat' strategy and wider access to drugs that bring down the viral load (VL), evaluating viral suppression would help to identify those requiring interventions and to make progress towards meeting the targets in Cameroon.

Methods A study was conducted from October 2015 to August 2017 amongst adults ( $\geq 20$ years), adolescents (10-19) and children (0-9) at $12,24,36$ and $\geq 48$ months on ART, monitored at the Chantal BIYA International Reference Centre for research on HIV/AIDS prevention and management (CIRCB) in Yaoundé, Cameroon. VL was established using Abbott m2000RT-PCR. VS was defined as VL $<1000$ copies/ $\mathrm{ml}$; with $\mathrm{p}<0,05$ considered significant.

Results A total of 1979 patients (70\% female) were enrolled (1825 adults, 112 adolescents, 42 children); 1865 were on first-line (NNRTI-based, duration: 48 [IQR 24-48] months) vs. 114 on second-line (PI/r-based, duration: 48 [IQR 36-48] months); with 19\%(368) at Month2, 14\%(274) at Month24, $10 \%(207)$ at Month36\% and 54\% (1130) at $\geq$ Month48. 